\title{
A Practical Assessment of Modern IT Project Complexity Management Tools
}

Citation for published version (APA):

Morcov, S., Pintalon, L., \& Kusters, R. J. (2021). A Practical Assessment of Modern IT Project Complexity Management Tools: Taming Positive, Appropriate, Negative Complexity. International Journal of Information Technology Project Management (IJITPM), 12(3), 90-108. [6]. https://doi.org/10.4018/ijitpm.2021070106

DOI:

10.4018/ijitpm.2021070106

Document status and date:

Published: 01/07/2021

Document Version:

Publisher's PDF, also known as Version of record

\section{Document license:}

Taverne

Please check the document version of this publication:

- A submitted manuscript is the version of the article upon submission and before peer-review. There can be important differences between the submitted version and the official published version of record. People interested in the research are advised to contact the author for the final version of the publication, or visit the DOI to the publisher's website.

- The final author version and the galley proof are versions of the publication after peer review.

- The final published version features the final layout of the paper including the volume, issue and page numbers.

Link to publication

\section{General rights}

Copyright and moral rights for the publications made accessible in the public portal are retained by the authors and/or other copyright owners and it is a condition of accessing publications that users recognise and abide by the legal requirements associated with these rights.

- Users may download and print one copy of any publication from the public portal for the purpose of private study or research.

- You may not further distribute the material or use it for any profit-making activity or commercial gain

- You may freely distribute the URL identifying the publication in the public portal.

If the publication is distributed under the terms of Article 25fa of the Dutch Copyright Act, indicated by the "Taverne" license above, please follow below link for the End User Agreement:

https://www.ou.nl/taverne-agreement

Take down policy

If you believe that this document breaches copyright please contact us at:

pure-support@ou.nl

providing details and we will investigate your claim.

Downloaded from https://research.ou.nl/ on date: 26 Apr. 2023 


\title{
A Practical Assessment of Modern IT Project Complexity Management Tools: Taming Positive, Appropriate, Negative Complexity
}

\author{
Stefan Morcov, Katholieke Universiteit Leuven, Belgium \\ Liliane Pintelon, Katholieke Universiteit Leuven, Belgium \\ Rob J. Kusters, Open Universiteit Nederland, The Netherlands
}

\begin{abstract}
Complexity is ubiquitous in modern engineering and project management. It is traditionally associated with failure. Also, complexity works! It delivers functionality, creativity, innovation. Complexity management contributes to the success of high-risk IT projects, helps better project understanding, allows for better prioritization and planning of resources. Managing negative complexity reduces project risk. Positive and appropriate complexity are catalysts for opportunities. This paper is a qualitative longitudinal study based on multiple industry project cases, consisting in the repeated evaluation of a set of complexity management tools. The tools were deployed in a classical process framework: plan, identify, analyze, plan responses, monitor, and control. The evaluated tools red-flag and measure complexity, analyze its sources and effects, and plan mitigation strategies. The study aims to provide project managers with methods for increasing project success rates and reducing failure in complex IT project environments.
\end{abstract}

\section{KEYWORDS}

Appropriate Complexity, Complex IT Projects, Complexity Management, Complexity Measurement, Opportunities, Positive Complexity, Project Management, Risk Management

\section{INTRODUCTION}

Today's engineering technology projects and products are larger, more complicated, difficult, complex. Project complexity strongly correlates with project failure, poor project management performance, and increased risk (Williams, 2005) (Patanakul, 2014) (Floricel, Michel, \& Piperca, 2016) (Bjorvatn \& Wald, 2018). IT projects have a high derail rate, with industry reports suggesting that only a handful are successful - between 16\% and 31\% (Standish Group, 1994) (Standish Group, 2014). While it is known that IT projects tend to have high-cost overruns on average, research shows that a surprisingly large number of IT projects incur massive cost and schedule challenges. In fact, one in six IT projects is expected to be "a black swan, with a cost overrun of $200 \%$, on average, and a schedule overrun of almost 70\%”. (Flyvbjerg \& Budzier, 2011). A significant number of IT projects are reporting incredible losses: Levi Strauss' SAP implementation was a \$5 million project that led to an almost \$200 million loss; the "Toll Collect" project cost Germany $\$ 10$ billion in lost revenue; the overall losses incurred by underperforming IT projects in the US is estimated at $\$ 55$ billion annually (Flyvbjerg \& Budzier, 2011). When the European Commission finally launched the Schengen Information System (SIS II) 
in 2013, the project was more than 6 years late and 8 times more expensive than the initial estimate, at a final cost of $€ 500$ million (European Court of Auditors, 2014).

Research in IT project complexity is thus particularly relevant for today's IT and software engineering environments. Complexity is a ubiquitous characteristic of contemporary engineering and project management. While complexity is traditionally associated with high-cost and high failure risk, the traditional approaches of simplifying and reducing complexity do not consider the essential benefits offered by technological and organizational complexity. We notice all around us that complexity works: it delivers advanced functionality to products such as smartphones, cars, spacecrafts; it supports innovation, creativity, adaptability and viability of organizations (Morcov, Pintelon, \& Kusters, 2020b) (Maurer, 2017) (Bar-Yam, 2003) (Stacey, 1995). While significant contributions have been made to understanding project complexity, there is still a strong need for practical tools that enable identification and analysis of project complexity and associated strategies, and for validation of such proposed tools.

The objective of this paper is to analyze why, when, and how specific tools for the management of IT project complexity should be applied, based on an assessment of their impact in practice. The evaluated tools were:

1. Red-flagging and measuring complexity: 3 complexity measurement tools.

2. Specialized tools for identification and analysis of complexity causes and effects, management, and mitigation of IT project complexity, designed and validated as part of a larger research project (Morcov, Pintelon, \& Kusters, 2020b).

The research method was a longitudinal evaluation based on the application and repeated evaluation of the said tools, in several project cases, with a live assessment of their impact in the respective projects. The main research approach was qualitative. The tool deployment process followed a standard process composed of: planning, identification, analysis, response planning, and monitoring and control. The evaluated tools were deployed, tested, and evaluated repeatedly with multiple participants, over a period of 7 months. They were tested in a real project context, in conjunction with other typical IT project management tools.

The paper brings insights from the industry that support and enhance project complexity management theory, and aims to provide project managers with more efficient theoretical and practical tools for driving project management performance and project success.

\section{LITERATURE REVIEW - STATE OF THE ART}

Complexity is a topic of more and more interest and an important aspect of IT projects. In recent years, project complexity research became more and more important. More than 50 peer-reviewed articles are now being published each year; far more than the 18 papers published in all the first cumulated 10 years when the concept of project complexity first appeared, in the early 1990s. These papers describe, define and measure project complexity, some by defining theoretical models or frameworks, some of them focused on various industries including IT. The literature is consolidated by several systematic reviews (Geraldi, Maylor, \& Williams, 2011) (Bakhshi, Ireland, \& Gorod, 2016) (Morcov, Pintelon, \& Kusters, 2020a). An overview of the main historical approaches to project complexity is presented in Table 1.

A complex project is difficult to understand, foresee and keep under control its overall behavior, even when given reasonably complete information about its individual components (Edmonds, 1999) (Vidal, Marle, \& Bocquet, 2011). A complex project is formed of several complex sub-systems: we develop complex IT products with complex IT projects for complex markets in complex organizations with complex processes (Morcov, Pintelon, \& Kusters, 2020b). 
Table 1. Approaches to project complexity

\begin{tabular}{|c|c|}
\hline Structural complexity & $\begin{array}{l}\text { Consisting of many varied interrelated parts. Typically expressed in terms of quantity, } \\
\text { variety, and interdependence of project components, and technological and organizational } \\
\text { factors of complexity (Baccarini, 1996) }\end{array}$ \\
\hline $\begin{array}{l}\text { Uncertainty, multiplicity, } \\
\text { ambiguity }\end{array}$ & $\begin{array}{l}\text { Uncertainty in goals and methods (Turner \& Cochrane, 1993) } \\
\text { Multiplicity (many approaches and end-states) vs. ambiguity (conflict and uncertainty in } \\
\text { decisions) (Kennedy, McComb, \& Vozdolska, 2011) }\end{array}$ \\
\hline Dynamic complexity & $\begin{array}{c}\text { Characterized by ambiguity, uncertainty, propagation, emergence, and chaos (Whitty \& } \\
\text { Maylor, 2009) (Marle \& Vidal, 2016) }\end{array}$ \\
\hline $\begin{array}{l}\text { Subjective (perceived), vs. } \\
\text { objective (or descriptive) } \\
\text { complexity }\end{array}$ & $\begin{array}{l}\text { The subjective complexity paradigm assumes that the complexity is always improperly } \\
\text { understood through the perception of an observer, while objective complexity considers it } \\
\text { as an intrinsic property (Marle \& Vidal, 2016) }\end{array}$ \\
\hline $\begin{array}{l}\text { Simple, complicated, } \\
\text { complex, and really } \\
\text { complex projects }\end{array}$ & $\begin{array}{l}\text { A complicated project is the sum of its parts. Structural complexity is considered } \\
\text { complicatedness, solvable with additional resources and decomposition (Maurer, 2017). } \\
\text { A complex project is more than the sum of its parts. It is characterized by unknown } \\
\text { unknowns, and emergence; where cause and effect can only be deduced in retrospect. } \\
\text { A very complex project, a.k.a. really complex, or chaotic, is different than the sum of } \\
\text { its parts. It is characterized by unknowables; where cause and effect are unclear even in } \\
\text { retrospect (Bakhshi, Ireland, \& Gorod, 2016). }\end{array}$ \\
\hline
\end{tabular}

Project Complexity Management is the project management Knowledge Area that includes processes to understand, plan strategy and responses, and manage project complexity (Morcov, Pintelon, \& Kusters, 2020b). The management of complex IT projects is an expensive activity, requiring special tools, expertise and skills, different from the traditional project management deterministic approaches (Daniel \& Daniel, 2018).

A typical project management process consists of phases such as: a planning phase; identification; analysis; developing strategies for mitigation; and monitoring and control (Figure 1, Table 2). Similar process structures are used in problem solving and problem management, risk management, vulnerability management, communications management (PMI, 2017) (Marle \& Vidal, 2016). A set of tools were identified for evaluation per each step of this process model (Table 2).

Identifying (recognizing) IT project complexity is the first and critical step in complexity management -i.e. red-flagging, categorizing and measuring. The identification of complex projects is important for the selection of the appropriate management tools. It is particularly important for

Table 2. Complexity management process

\begin{tabular}{|c|c|c|c|}
\hline & Phase & Objectives & Tools selected for testing \\
\hline 1 & $\begin{array}{c}\text { Plan IT Complexity } \\
\text { Management }\end{array}$ & $\begin{array}{c}\text { Initial complexity assessment } \\
\text { Tool selection }\end{array}$ & $\begin{array}{c}\text { CIFTER } \\
\text { Hass } \\
\text { Morcov }\end{array}$ \\
\hline 2 & $\begin{array}{c}\text { Identify IT project } \\
\text { complexity }\end{array}$ & Problem detection, inventory, and description & $\begin{array}{c}\text { Checklists: Hass, CIFTER, Morcov } \\
\text { tools, CES, COSM }\end{array}$ \\
\hline 3 & $\begin{array}{c}\text { Analyze project } \\
\text { complexity }\end{array}$ & Analysis - understanding & $\begin{array}{c}\text { Complexity Effect Scale (CES) } \\
\text { Complexity Source/Effect } \\
\text { Segmentation Matrix (CoSM) }\end{array}$ \\
\hline 4 & $\begin{array}{c}\text { Plan response } \\
\text { strategy }\end{array}$ & Design of potential solutions & $\begin{array}{c}\text { Mitigation Strategy Matrix (MSM) } \\
\text { and control }\end{array}$ \\
\hline 5 & $\begin{array}{c}\text { Manage, monitor } \\
\text { and }\end{array}$ & Implementation of the strategy & Updates to the tools \\
\hline
\end{tabular}




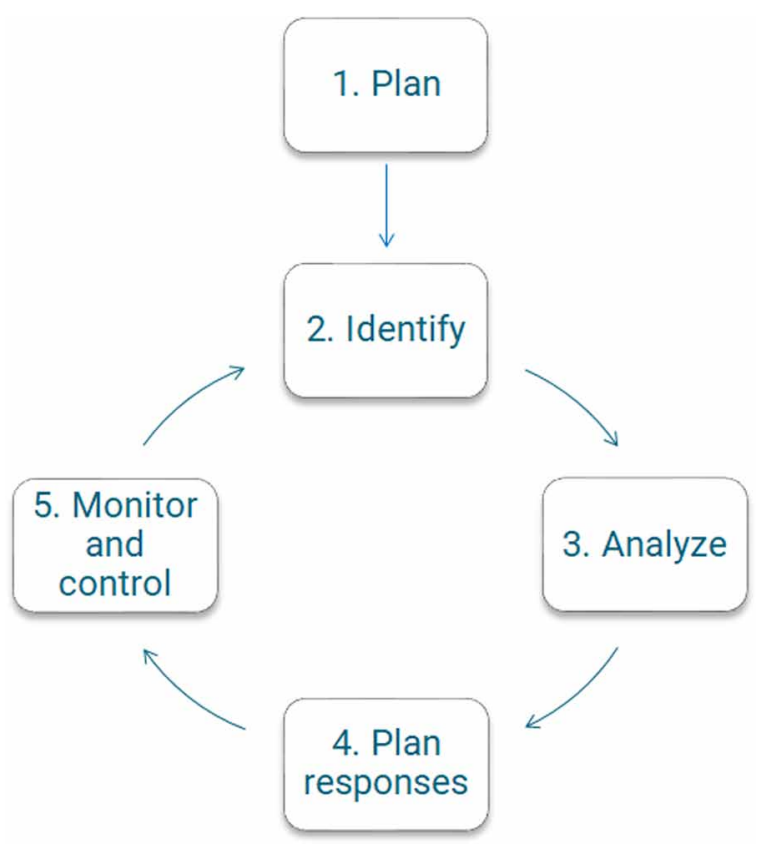

strategic and project portfolio management (Vidal, Marle, \& Bocquet, 2011). Several complexity measurement tools were proposed:

1. The Crawford-Ishikura Factor Table for Evaluating Roles (CIFTER) supported by the International Project Management Association (GAPPS, 2007) - 7 qualitative criteria, Likerttype ordinal scale from 1 to 4 (low, moderate, high, very high) without midpoint; not weighted; general purpose.

2. Hass' Project Complexity Model Formula (Hass, 2008) - simple and short, 5 qualitative complexity dimensions (11 in the extended version); ordinal scale from 1 to 3 , with midpoint (low, moderate, high); not weighted; general purpose.

3. IT project complexity scale (Morcov, Pintelon, \& Kusters, 2020a) - medium-level of detail, 28 questions, interval scale for qualitative questions and ratio scale for quantitative questions, specialized for IT.

4. Other general-purpose tools: (PMI, 2014) (Dao, 2016) (Vidal, Marle, \& Bocquet, 2011) (CDG \& DMO, 2012) (Treasury board of Canada secretariat, 2015).

The Complexity Effects Scale (CES) tool provides a formal method to analyze complexity based on its effects, while the Complexity Source/Effect Segmentation Matrix (CoSM) tool supports the identification and analysis based on both sources and effects (Morcov, Pintelon, \& Kusters, 2020b).

Negative complexity is the complexity that hinders project management performance and project success. Traditionally, both research and practice focus only on the negative effects of complexity, on the relation between complexity, risk, and failure. Still, complexity is sometimes required (or requisite, or appropriate), and even positive. Complexity is needed to ensure system viability; enhances creativity and innovation; offers functionality (Beer, 1972) (McKelvey \& Boisot, 2009) (Floricel, Michel, \& Piperca, 2016) (Maurer, 2017). 
Appropriate (or requisite) complexity is the complexity needed for the project to reach its objectives, or whose contribution to project success balances the negative effects, or the cost of mitigation outweighs negative manifestations.

Positive complexity is the complexity that adds value to a project, and whose contribution to project success outweighs the associated negative consequences (Morcov, Pintelon, \& Kusters, 2020b). Since it creates opportunities, it should be exploited rather than eliminated.

The Mitigation Strategy Matrix (MSM) is a tool that supports planning complexity response strategies, similarly to risk or vulnerability management (Table 5) (Morcov, Pintelon, \& Kusters, 2020b).

Table 6 presents a Complexity Register that helps with the collection, organization, and analysis of the data resulting from the application of the CES, COSM, MSM tools.

\section{Methods}

The research approach was qualitative: a longitudinal study, based on multiple project cases, consisting in the repeated evaluation of a set of tools for the identification, analysis, and management of IT project complexity. The evaluated tools are listed in Table 2 .

Table 3. Complexity Effect Scale (CES) example

\begin{tabular}{|c|c|c|}
\hline Positive complexity & Appropriate complexity & Negative complexity \\
\hline Benefits $>$ Cost & Benefits $\simeq$ Cost & Benefits $<$ Cost \\
\hline Desirable & Accepted & Undesirable \\
\hline $\begin{array}{l}\text { Large budget } \\
\text { Reusability }\end{array}$ & $\begin{array}{c}\text { Political priority } \\
\text { New technology } \\
\text { Unclear objectives - scope agility }\end{array}$ & $\begin{array}{l}\text { Many varied inter-dependent technologies } \\
\text { and components. } \\
\text { Unclear objectives. } \\
\text { Large number and variety of stakeholders. }\end{array}$ \\
\hline
\end{tabular}

Table 4. Complexity Source/Effect Segmentation Matrix (CoSM) example

\begin{tabular}{|c|c|c|}
\hline $\begin{array}{c}\text { Effects } \\
\text { Sources }\end{array}$ & Positive \& Appropriate & Negative \\
\hline Internal & Reusability & $\begin{array}{c}\text { Many varied inter-dependent } \\
\text { technologies }\end{array}$ \\
\hline External & $\begin{array}{l}\text { Large budget, political priority. } \\
\text { New technologies. } \\
\text { Unclear objectives - scope agility }\end{array}$ & $\begin{array}{c}\text { Large number and variety of } \\
\text { stakeholders. } \\
\text { Unclear objectives }\end{array}$ \\
\hline
\end{tabular}

Table 5. Mitigation Strategies Matrix (MSM)

\begin{tabular}{|c|c|c|c|}
\hline \multirow{2}{*}{ Response strategy } & \multicolumn{2}{|c|}{ Complexity Effect } \\
\cline { 2 - 4 } & Positive & Appropriate & Negative \\
\hline Create, enhance & $\mathrm{X}$ & & \\
\hline Use (exploit) & $\mathrm{X}$ & $\mathrm{X}$ & $\mathrm{X}$ \\
\hline Accept / ignore & $\mathrm{X}$ & & $\mathrm{X}$ \\
\hline Simplify / reduce & & & $\mathrm{X}$ \\
\hline Avoid / eliminate & & & \\
\hline
\end{tabular}


Table 6. Complexity Register (CoRe) form

\begin{tabular}{|c|c|c|c|c|}
\hline $\begin{array}{c}\text { Complexity element, } \\
\text { Description }\end{array}$ & Effect (CES) & $\begin{array}{c}\text { Source } \\
\text { (CoSM) }\end{array}$ & $\begin{array}{c}\text { Mitigation Strategy } \\
\text { Matrix (MSM) }\end{array}$ & $\begin{array}{c}\text { Strategy, risks and } \\
\text { opportunities }\end{array}$ \\
\hline & $\begin{array}{c}\text { Positive, Negative, } \\
\text { Appropriate }\end{array}$ & & Response strategy & $\begin{array}{c}\text { Details of the response } \\
\text { strategy }\end{array}$ \\
\hline
\end{tabular}

A set of classic tools were also included in the evaluation: stakeholder map, communication plan, risk register, SWOT. This had the purpose of providing a common ground in the discussions with the case study participants, and a practical comparison between well-known tools and the less-known specialized tools that were evaluated.

The tools were tested in actual complex IT projects, and monitored over a period of several months. The research is thus more than an assessment of the opinion of experts: it is an evaluation of benefits and results in actual projects.

The qualitative exploratory approach was chosen due to the novelty of the topic (Levitt, et al., 2018) (Gummesson, 2000). The analysis of the case studies included (Yin, 2011) collecting data and testing the tools in the actual projects, by application mostly during live interviews. Face-to-face, open interviews are suitable because of the novelty of the research problem, and the overloaded nonstandardized terminology of the domain. They support qualitative exploratory research.

All discussions and interviews were video-recorded, for further in-depth text and feedback analysis, and to ensure construct validity.

The research had the following activities:

- Research design.

- Case study execution.

- Analysis and interpretation of the research results.

\section{Research Design}

This activity consisted of: 1) defining the research methods; 2) selection of the project cases and participants; 3) design of the templates and questionnaires.

The projects selected for the research are large IT projects, (presumably) complex; accessible to researchers. The projects should be in an early stage in their lifecycle, in order for the tools to have an impact on the respective projects, thus allowing for a meaningful evaluation.

The participants involved in the case studies are project managers and top management. They should be accessible, willing, and senior - with significant IT management experience. The personal involvement of the participants (skin in the game) ensures their involvement, personal feedback, focus on practical results and efficiency. Project managers must have detailed project knowledge, and direct responsibility. Top management also should have reasonable know-how of the actual projects, as well as significant general experience.

Templates and questionnaires were designed in spreadsheet form, to support the deployment of the tools and the collection of case study data. For each project, 3 categories of information were collected:

1. General project information.

2. Forms for deploying the evaluated tools.

3. Evaluation questionnaire. 
The evaluation questionnaire was filled-in during the live interviews. It consisted of 2 questions for each evaluated tool: a quantitative Likert question, and an open exploratory free-text question:

1. Closed quantitative question: How useful is this tool - i.e. benefits outweigh the effort? Answers are recorded on a Likert-type interval scale, from 1 (not useful, i.e. zero) to 4 (very useful); forced-choice, i.e. without a midpoint so as to avoid neutral/indecision answers; allowing a separate out-of-scale point for non-answer; with no definition for in-between values (i.e. 2, 3) so as to allow limited numeric analysis (Chyung, Roberts, Swanson, \& Hankinson, 2017).

2. Open qualitative exploratory question: How did this tool help? Why, why not, when?

\section{Case Study Execution}

This activity consisted of: a) preliminary desk research; b) 2 rounds of interviews with project cases participants; c) 1 round of interviews with top management.

a) The desk research consisted of gathering project information: objectives, stakeholders, environment, duration, size, technology, team, context, methodologies, and tools.

b.1). The initial live interview/meeting with each case study participant consisted of:

- Presentation of the tools, terminology, definitions.

- Complexity measurement of each project.

The measurement was done independently for each project, and for each participant.

Multiple perspectives (data points) were collected per each case study, with up to 4 participants per project, to ensure triangulation. Thus, the forms were filled-in by each participant independently, with minimum external influence. This allowed participants to have a personal first-hand experience with the measurement tools. It also helped avoid external influence, groupthink, or peer-pressure bias.

\section{- Interactive application of the complexity management tools.}

A single Complexity Register (CR) form was filled per project, aggregating all project information and all perspectives, from all participants, and visible to all of them.

The application of management tools, especially novel, cannot be a neutral data collection activity. In practice, it is a mix of research and consulting, where it is sometimes difficult to establish a clear boundary between the role of academic researcher, and that of management consultant. Known as the action research paradigm, this mix of roles is more and more recognized in management research as valuable for these situations (Gummesson, 2000). In fact, the application of qualitative tools followed a scenario typical for management meetings; where participants analyze a situation interactively, openly, increasing the overall creativity, favoring the exploration of new ideas, generating potential solutions and scenarios; establishing action plans; and in general taking decisions as a group.

- The tools evaluation questionnaire was applied individually, 1-to-1, during each live meeting. It was recorded as neutrally as possible from each participant, with answers from other participants hidden, in order to avoid influencing and increase objectivity.

b.2) The live follow-up meetings with each participant had the objectives: to obtain longitudinal feedback, and to assess any change in perception after the practical application of the tools in the actual projects. They were executed after at least 3 months from the initial interview, in order to provide participants sufficient time to analyze the tools, to potentially use them 
independently, to observe their impact during the actual project's execution, in order to provide conclusions. During the follow-up meeting, the tools and data are reviewed, the forms and Complexity Register were updated. The evaluation questionnaire was applied again, this time focusing on how useful the tool was in the actual project.

c) Top management interviews were performed in order to obtain a higher-level view and feedback on the case study results. The evaluation questionnaire was applied during these interviews with a focus on the overall results, benefits and costs of the application of the tools; on the usefulness of the tools from the perspective of a portfolio manager. This evaluation was done only once, at the end of the case studies.

\section{Analysis and Interpretation of the Research Results}

This activity consisted of: 1) extraction of text transcripts from each video recording; 2) quantitative analysis; 3) qualitative analysis of the evaluation questionnaires and interview transcripts.

The quantitative analysis included mostly descriptive statistics, as the number of data points does not allow detailed statistical analysis.

The qualitative analysis used card-sorting (Spencer \& Warfel, 2004):

1. A list of arguments was extracted from each transcript, with particular attention to contextual information, e.g. when and why a particular tool was or was not useful.

2. These were organized and classified per question and across interviews; each appearance was documented so as to ensure traceability. The classification process followed the criteria for categorization of data of (Merriam, 2009).

\section{LIMITATIONS, VALIDITY, AND RELIABILITY}

During our research process, we embraced the fact that qualitative research is a personal journey (Gummesson, 2000).

Construct validity and reliability were strengthened through: a) the use of multiple sources of evidence (triangulation), i.e. analyzing several projects and several stakeholders for each project; b) establishing and documenting the chain of evidence, through video recording, text transcripts, and rigorous configuration management; c) ensuring that stakeholders have open access for reviewing the collected information, including access to video recordings and data.

Triangulation supports proving convergence and exploring divergent possibly new relevant insights. Multiple case studies are suitable for building new theories and their external validation (Gibbert \& Ruigrok, 2010). Face-to-face interviews are suitable for the niche topic, to obtain new insights and increase innovation and creativity. The interviews were structured, but had open questions to drive exploratory qualitative research. The evaluation scale omitted the midpoint in order to increase reliability, as the topic is unfamiliar, thus respondents might be very likely to misuse it (Chyung, Roberts, Swanson, \& Hankinson, 2017). During the open questions, stronger importance was placed on negative rather than on positive feedback; on discovering arguments, causality, and context (Wieringa, 2014).

The external validity of the research is affected by limitations regarding the project and organizational context. All projects included in the research are IT/software development projects and use similar project management and software development methodologies; but they cover a very wide range of technologies and business areas. The customers belong to several industry verticals, are both public and private organizations. All customers are Western European, but they are large multinational and multicultural organizations.

Any quantitative analysis must be interpreted with caution, considering the number of data points and the use of multiple ordinal and interval Likert-type scales. The analysis focuses therefore on the 
Table 7. Project cases summary

\begin{tabular}{|c|c|}
\hline & TOTAL \\
\hline Participants & 18 \\
\hline Interviews & 23 \\
\hline Project size (man-days) & $500-15000$ \\
\hline Project duration & $0.5-4$ years \\
\hline
\end{tabular}

qualitative analysis of the answers received, and of the type of arguments used by each participant, while taking into consideration the characteristics of the experts, organizations, and projects.

The measurement tools were evaluated in comparison with each other.

All the tools were deployed and evaluated as a set, making it difficult to differentiate in detail between the results and impact of each tool, independent of the others.

The participants have a personal stake in the projects (skin in the game), are personally interested in the success and results of the specific project cases. Their time is limited; nevertheless, they volunteer for this research. They have direct responsibility over the project's objectives, including cost, quality, deadlines, and scope - hence personal interest to limit the cost and overhead, but willing to adopt new methods and tools if useful. They have a genuine interest in advancing project management knowledge, in improving practice.

\section{RESULTS}

\section{Execution of the Project Case Studies}

The research consisted of the longitudinal, repeated evaluation of a set of tools, in 5 live ongoing projects (Table 7). The research spanned over 7 months, between May-Dec. 2020. It included 23 interviews.

All projects are IT/software, with thousands of man-days of effort, several years duration, many stakeholders. Each includes several technologies and business areas: web development, mobile applications, cloud/DevOps, e-Commerce, e-Learning, policy, e-Government. All are executed and delivered in Europe. All customers are multinational organizations based in western Europe (Belgium, Italy, and the UK) - a private global corporation, 4 European Union public institutions. All are international projects, with cross-national, multinational teams. Each project has many varied stakeholders, located in 2-38 countries per project, including administrative and business units, users, consortium partners, engineering teams, suppliers, and subcontractors - each based in different countries and locations. The language of all projects is English.

Between 1-4 participants were involved in each case study: the project manager, account manager, technical project manager (only one case), the former project manager (one case), customer project manager (one case). Each interview was 1-to-1. All meetings were organized over videoconference, due to the Covid pandemic crisis of 2020. All meetings were video recorded.

The tested tools were used directly by participants, during the live interviews. In 2 cases, participants also used the tools independently, off-line, between the live interviews - which allowed deeper insights and a more relevant evaluation.

The complexity measurement tools were applied independently, during the first interview with each participant; they were not repeated in the second interview with the same person, since measurement is an initial assessment, part of the project planning phase. Each measurement was done independently, with participants not being influenced by the results of their colleagues. For each project, between 1-3 distinct measurements were done with each tool. Filling-in the measurement forms resulted, in practice, in collecting detailed, relevant project information. 
Figures 2 and 3 present the results of measuring using CIFTER and Hass, per project and per criterion. The detailed results for all tools are available on request from authors.

The measurement results support a good degree of agreement across tools, as well as across participants. Project Prj2 is not confirmed to be complex, with its normalized results of $19 \%, 32 \%$, $27 \%$ per each scale, respectively. This makes it an outlier for several other evaluation criteria as well. Project Prj1 was confirmed as complex, with results of 18, 58 and 65\% respectively. Projects Prj3, Prj 4 and Prj5 were confirmed to be very complex, with results between $58 \%$ and $81 \%$ per each scale.

Figure 4 presents the average results of the measurement per project and per tool. The scale of each measurement tool is different, but for graphical illustration purposes, the results were normalized to a $0-100 \%$ scale. Further aggregation of the data is difficult, considering that 2 scales are arguably ordinal; that each tool uses a different scale; and that the number of data points is limited.

The identification and analysis of complexity was done during the live interviews, by filling-in a Complexity Register form, per each project.

The analysis of the elements of complexity and their effects, i.e. positive, appropriate and negative, was done in-depth, according to the Complexity Effects Scale (CES). This was the key factor in planning mitigation strategies. On the other hand, the detailed analysis of the sources of complexity (as proposed by CoSM) was discontinued after the first 3 interviews. In fact, during these interviews, it was observed that the level of detail and thus the effort required for a rigorous source analysis would be too high, compared to not obvious benefits.

Figure 2. CIFTER complexity scale - averages per project and criterion

\begin{tabular}{|c|c|c|c|c|c|}
\hline 4.0 & & & & & \\
\hline 3.5 & & & & & \\
\hline 3.0 & & & & & \\
\hline 2.5 & & & & & \\
\hline 2.0 & & & & & \\
\hline 1.5 & & & & & \\
\hline 1.0 & & & & & \\
\hline 0.5 & & & & & \\
\hline 0.0 & Prj1 & Prj2 & Prj3 & Prj4 & Pris \\
\hline EStability of the overall project context & 3.0 & 2.0 & 2.7 & 4.0 & 2.0 \\
\hline $\begin{array}{c}\text { Number of distinct disciplines, methods, or } \\
\text { approaches involved in performing the } \\
\text { project }\end{array}$ & 1.5 & 1.0 & 3.7 & 4.0 & 3.0 \\
\hline $\begin{array}{l}\text { Magnitude of legal, social, or } \\
\text { environmental } \\
\text { implications from performing the project }\end{array}$ & 2.5 & 2.0 & 1.0 & 3.0 & 4.0 \\
\hline $\begin{array}{c}\text { Overall expected financial impact (positive } \\
\text { or } \\
\text { negative) on the project's stakeholders }\end{array}$ & 3.5 & 1.5 & 3.0 & 3.0 & 4.0 \\
\hline $\begin{array}{l}\text { N Strategic importance of the project to the } \\
\text { organization or the organizations involved }\end{array}$ & 3.5 & 1.0 & 3.0 & 2.0 & 4.0 \\
\hline $\begin{array}{l}\text { Stakeholder cohesion regarding the } \\
\text { characteristics of the product of the project }\end{array}$ & 2.5 & 2.5 & 3.7 & 4.0 & 2.0 \\
\hline $\begin{array}{c}=\text { Number and variety of interfaces between } \\
\text { the project and other organizational } \\
\text { entities }\end{array}$ & 4.0 & 1.0 & 3.7 & 4.0 & 3.0 \\
\hline
\end{tabular}


Figure 3. Hass complexity scale - averages per project and criterion

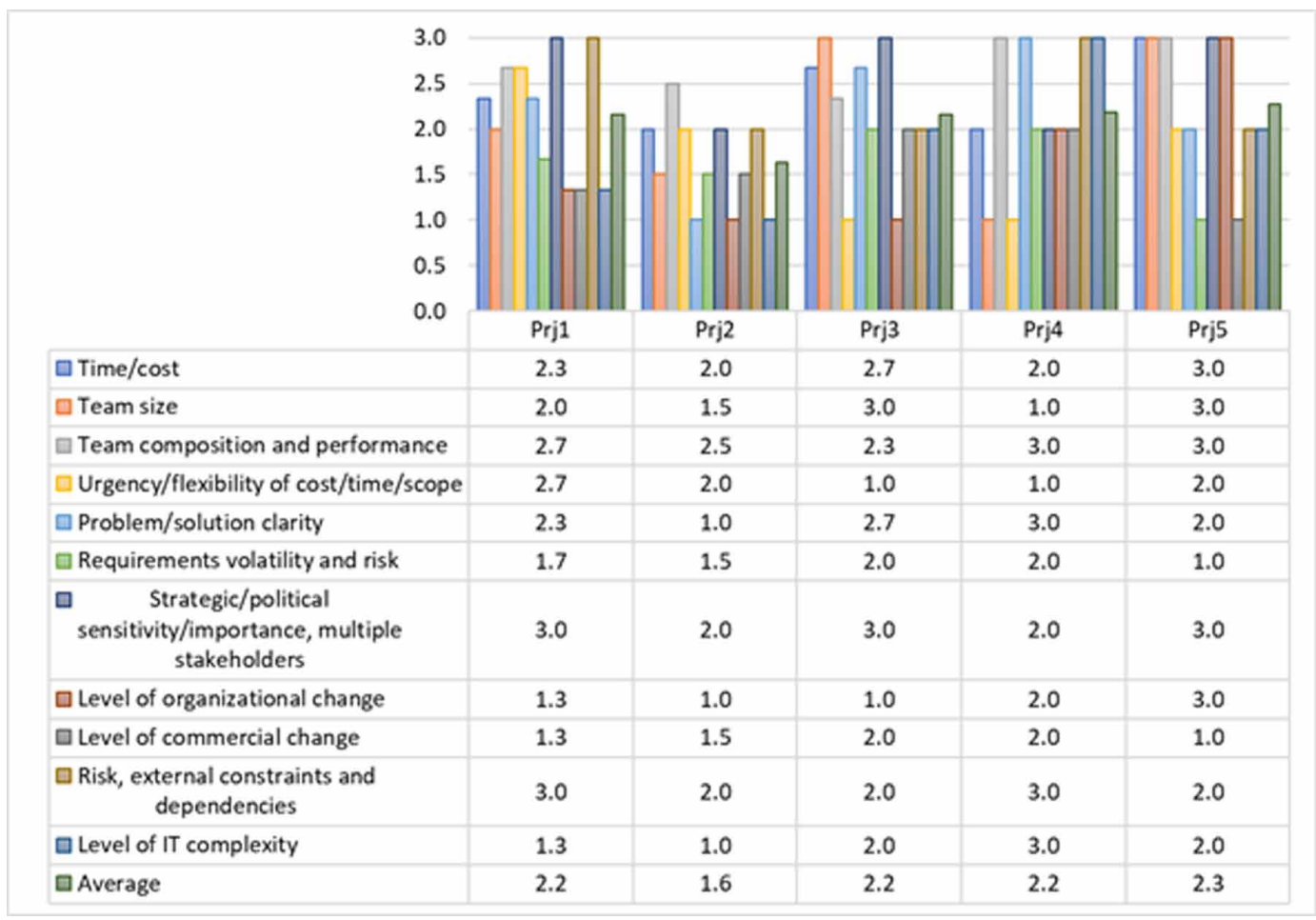

Figure 4. Average complexity, per project and measurement tool

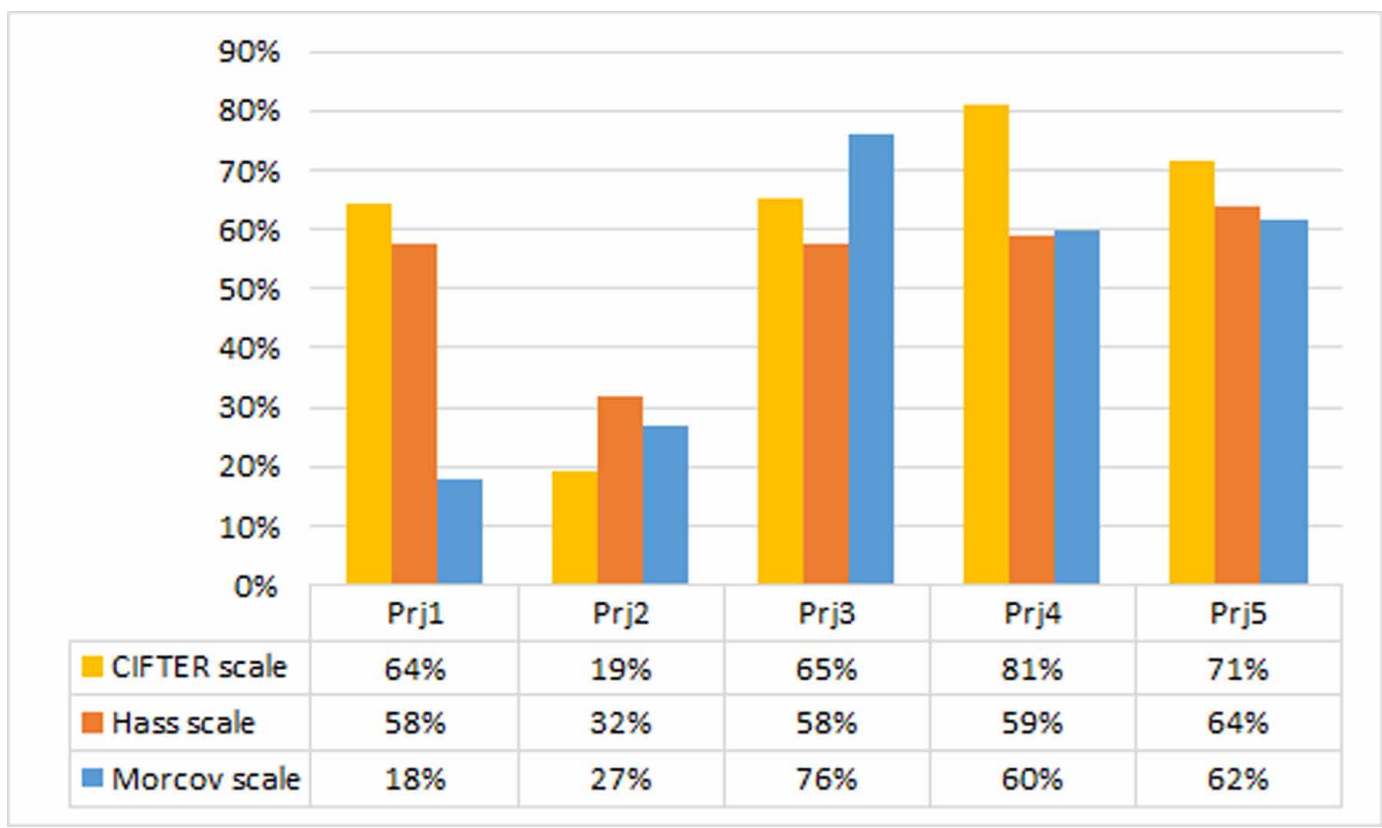




\section{Tools Evaluation}

The quantitative assessments of the tools are presented in Figure 5, by project, by group of participants, as well as aggregated. The scale used was Likert 1-4.

The quantitative assessment was supplemented by a qualitative analysis: each assessment being detailed with an in-depth research, looking for arguments such as: How did this tool help, why, why not, when. The list of qualitative arguments was extracted from the interview transcripts and organized using card-sorting.

In general, project Prj2 shows divergent results because it was not confirmed to be complex.

Measuring Project Complexity is considered useful by all participants, with an average score of 3.1 (on the scale of 1 to 4), and with positive results for each group: 2.8 for project managers, 3.5 for top- and portfolio-management, 3.7 for top-management. The measurement tools considered most useful are Morcov and Hass. The evaluation results show a good degree of agreement across participants and types of participants, with low variation coefficients.

The risk register, agile approach, and stakeholder map are the most valued traditional tools for managing complexity. The communication plan is considered a valuable tool. The SWOT tool received inconclusive assessments, mostly negative, and high variation coefficients between participant groups. Other traditional tools voluntarily suggested were: decomposition/WBS, knowledge management/ collaboration, planning tools (3 mentions each), dependency modeling/traceability, delegation (2 mentions).

The specialized tools for complexity analysis and management received positive assessments, but with important differences between groups. Project managers have positive convergent assessments regarding the benefits of dedicated complexity analysis and management, and analysis of effects such as positive complexity; with low variation coefficients i.e. good alignment of opinions. The variation coefficients are increasing when including other participants, showing divergence between groups: top management gave lower scores than project managers. An explanation could be lower social desirability and acquiescence biases for top management. Top management motivated the low scores with the overhead incurred by deploying additional tools. They acknowledge the value of the tools, and suggested instead to upgrade current risk management processes by including complexity, rather than adding new tools.

Table 8 details the arguments proposed spontaneously by participants, as answers to the open questions and discussions. These arguments were identified from the interview transcripts, through text analysis; then classified and organized using card sorting. The numbers represent how many participants proposed each argument spontaneously, unsolicited. The count is therefore significant, but it doesn't represent a ranking. Noticeably, some arguments contradict each other.

\section{DISCUSSION}

\section{Tool Selection and Timing}

Most participants support that analysis and management tools should be deployed as early as possible in a project lifecycle; 8 participants giving this argument, but also with 2 contrary positions. The participants concurred that the tools and data should be continuously updated throughout the project. The majority underlined that a tool is useful only if it generates actions. A participant suggested that the effectiveness depends on the dissemination and sharing of results and actions with the project team and stakeholders.

Participants support the standardization of a clear set of tools and templates at the level of the organization, adapted to the organizational and project context, and easily reusable across projects.

The arguments given especially by top management participants suggest that deploying too many tools is counter-efficient, thus tools should be prioritized depending on the project. 


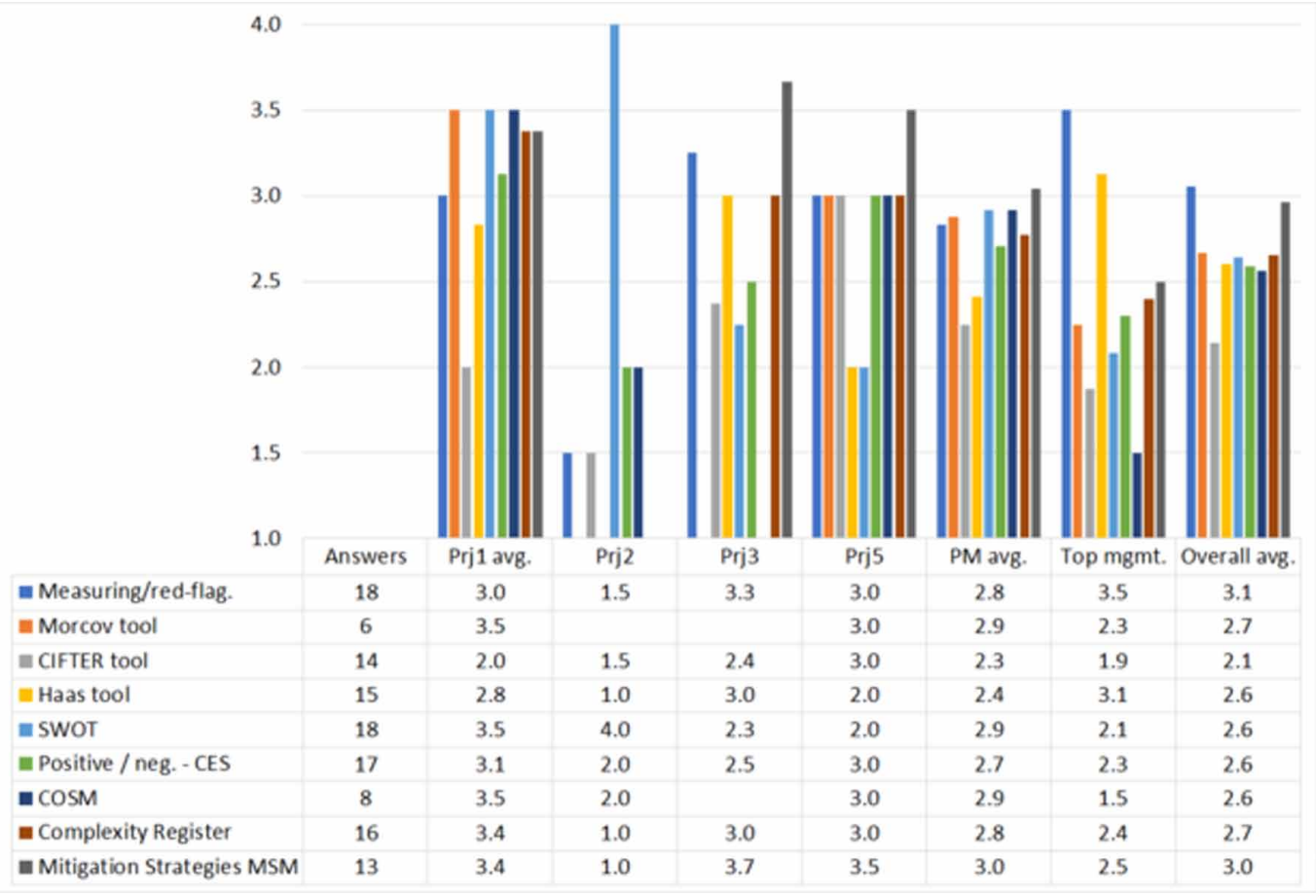

\section{Red-Flagging vs. Detailed Complexity Analysis}

When deciding on the deployment of additional management tools, an important discussion was the cost-benefit analysis. 7 participants gave spontaneous arguments that the overhead is not acceptable for simple or small projects. Only projects "red-flagged" as potentially complex high-risk should enter in a detailed complexity assessment or measurement; and be considered for the application of specific complexity management tools. This red-flagging should be automated, low-effort, e.g. using numeric size-related information, easily available, but which strongly correlate with complexity, such as: budget, number of stakeholders, subcontractors. Participants also argued that "high-risk" should also be an independent flag.

\section{Complexity Measurement Scales}

This study tested 3 measurement tools, for a comparative evaluation. Participants concur that only one tool should be standardized at the level of an organization. Such a tool should be as simple and objective as possible - and at the same time should offer sufficiently detailed criteria. Simple projects should not be included in a detailed complexity measurement. For complex projects, participants argued that an effort of 10-60 minutes is acceptable for a detailed measurement. For very complex projects, a detailed tool such as the Morcov scale can constitute a very detailed checklist that supports an in-depth project analysis, useful for project analysis during initiation.

The CIFTER and Hass tools use similar criteria and scales. Accordingly, based on an odds ratio analysis, they yield reasonably similar results - of course, the number of data points is too limited to allow for a significant statistical conclusion (Table 9). Hass is better adapted to IT projects and includes more numeric criteria, thus it is more objective and easier to apply. Participants argued that they can instantly provide answers to numeric questions such as project budget, team size, or duration, 
Table 8. Qualitative analysis of the arguments of research participants (selection)

\begin{tabular}{|c|c|}
\hline Argument & Mentions \\
\hline \multicolumn{2}{|l|}{ Why is complexity management useful } \\
\hline It generates risk & 7 \\
\hline Supports to prioritize and plan projects in a portfolio & 1 \\
\hline Better allocation of resources & 3 \\
\hline Helps to understand the project & 2 \\
\hline \multicolumn{2}{|l|}{ When is complexity management (not) useful? } \\
\hline Useful (only) for large/complex projects & 7 \\
\hline For risky projects, because risk also generates complexity & 2 \\
\hline Mostly at project inception. Usefulness is low in advanced stages & 8 \\
\hline Not useful immediately at project start - because the information is not available yet & 2 \\
\hline Should be continuously updated throughout the project lifecycle & 3 \\
\hline A tool is important only when it generates actions & 7 \\
\hline $\begin{array}{l}\text { Only for reducing complexity - never to increase it (complexity can be appropriate, or requisite; but never } \\
\text { positive) }\end{array}$ & 1 \\
\hline \multicolumn{2}{|l|}{ Why is complexity management NOT useful } \\
\hline Overlaps too much with risk management & 5 \\
\hline \multicolumn{2}{|l|}{ Differences between complexity and risk management } \\
\hline Complexity management focuses on positive complexity, on opportunities & 5 \\
\hline $\begin{array}{l}\text { Complexity management supports 1) systemic thinking; and 2) awareness regarding opportunities - even } \\
\text { if a specific complexity management tool is not applied systematically }\end{array}$ & 2 \\
\hline \multicolumn{2}{|l|}{ How to apply complexity management tools } \\
\hline $\begin{array}{l}\text { Should be applied in } 2 \text { steps: red-flagging first, then detailed analysis and management - only for very } \\
\text { complex projects. }\end{array}$ & 7 \\
\hline $\begin{array}{l}\text { Project managers should receive detailed guidelines on how to apply the tools (e.g. templates, checklists, } \\
\text { tutorial, methodology) }\end{array}$ & 3 \\
\hline $\begin{array}{l}\text { A detailed tool (such as Morcov measurement scale) is essential as a checklist, identification and analysis } \\
\text { tool for large complex projects }\end{array}$ & 4 \\
\hline In order to be effective, tools should be adapted to the project environment & 2 \\
\hline $\begin{array}{l}\text { Project managers should share the results with the team and stakeholders; including business analysts, } \\
\text { management, customer }\end{array}$ & 1 \\
\hline The risk register should be upgraded to include complexity analysis and management & 3 \\
\hline A tool must be deployed uniformly (standardized) across an organization & 2 \\
\hline Project manager experience is essential & 1 \\
\hline Deploying too many tools is overhead, so tools should be prioritized & 3 \\
\hline
\end{tabular}

while significant effort is needed for answering abstract criteria. Numeric criteria alone though are not sufficient, as they do not cover non-quantifiable aspects such as dynamic complexity.

The ordinal scale of CIFTER and Hass can yield paradoxical results, not segregating between very different project sizes, when above the maximum threshold. Morcov scale uses a ratio scale, with divergent results. 
Table 9. Odds ratio analysis of the results of the measurement tools

\begin{tabular}{|c|c|c|c|c|c|c|c|}
\hline & Prj1 & Prj2 & Prj3 & Prj4 & Prj5 & Overall & $\begin{array}{c}\text { Overall } \\
\text { excluding } \\
\text { outlier Prj2 }\end{array}$ \\
\hline Odds ratio CIFTER/Hass & $112 \%$ & $60 \%$ & $113 \%$ & $137 \%$ & $112 \%$ & $112 \%$ & $101 \%$ \\
\hline Odds ratio Morcov/CIFTER & $28 \%$ & $141 \%$ & $117 \%$ & $74 \%$ & $86 \%$ & $80 \%$ & $89 \%$ \\
\hline Odds ratio Morcov/Hass & $31 \%$ & $85 \%$ & $132 \%$ & $101 \%$ & $97 \%$ & $90 \%$ & $90 \%$ \\
\hline
\end{tabular}

The tools and their scales should be adapted to the organization and environment, as the same project may be considered small or large, simple or complex, in different contexts. Tools standardization ensures comparability.

Complexity measurement tools will always have a certain degree of subjectivity, as numerous tools in social sciences and even engineering do.

\section{Checklists and Templates for Analysis}

The first application of a new tool, by a new user, in a new organization, is a difficult task, as there is no previous experience nor starting point. Templates are then gradually developed; artifacts are reused. The current project cases faced a similar challenge, participants asking for guidelines, templates, checklists, tutorials; and developing them as needed. The Complexity Register itself emerged as a checklist and template.

The measurement tools proved very useful for the identification and analysis of complexity. Morcov tool was considered more useful, being more detailed, precise, and adapted to IT. The simple application of such a measurement tool is therefore a detailed complexity and risk identification and analysis activity, necessary in fact for any project, as part of project initiation. As one participant suggested: "Any tool that supports to identify and mitigate risks is super useful"; or another participant: "the items in the Morcov scale are the same elements that are typically included in the project charter; analysis which is done during the initiation stage of any large project. [...] The finality - the operational results - is the identification of complexity elements and risks.". At the same time, checklists should not block creative thinking, nor limit the analysis to predefined patterns only.

\section{Risk vs. Complexity}

The study confirmed a strong relationship and even overlap between risk and complexity. Participants concur that complexity generates risk, but 2 spontaneous arguments argued that risk also generates complexity, which is aligned with the observation that ambiguity and uncertainty are at the same time risks and complexity aspects.

Overlap between different tools is common in project management; the exact toolset should be selected by the project manager and/or PMO for each organization and project.

The main difference is that risks are discrete events, occurring at specific moments, whereas complexity is systemic. Thus, risk management tends to be reactive to negative external events, whereas complexity is proactive and centered on internal opportunities. Noticeably, participants had difficulty differentiating between risk and complexity. Also, opportunities are considered a business/ sales topic, and disregarded by participants in the context of project management. This made positive complexity a valuable tool in practice: "I like the complexity register because it forces me to look at opportunities instead of only at risks”, was an argument received.

Awareness of the complexity theory proved already beneficial, supporting systemic thinking and openness towards positive complexity and opportunities in the actual project cases.

A potential solution to the overlap, suggested by 3 participants independently, is extending risk tools with complexity management: "Complexity should not be duplicated with risk. Deploying 2 
separate registers will lead to rejection. As the concept is useful, the key question is how to combine complexity and risk management. A detailed complexity measurement tool could be used as a tool to fill in a risk register, rather than a finality in itself".

\section{CONCLUSION}

This research consisted in the implementation and repeated evaluation of a set of tools for complexity measurement, analysis, and management, in 5 actual industry IT project cases, over a period of 7 months. The tools evaluated were: 3 complexity measurement tools; a set of traditional project management tools; and a set of specialized complexity management tools.

The results support the conclusion that, from the panoply of traditional project management tools, risk management, stakeholder and communication management are valued the most for managing complexity, as well as agile development methods and program management.

The results suggest that, for complex high-risk IT projects, and noticeably not for small/simple projects, complexity may be tamed with specialized tools such as those evaluated in the current study. By adopting a systematic and rigorous approach to complexity management, project managers can better understand and manage projects, mitigate the effects of negative complexity, reduce project risk, and support overall project success. Of course, there is no silver bullet with regards to the selection of the right tool or strategy, the solution being always contextual.

The results support the modern positivist approach to complexity, that complexity is ubiquitous in contemporary engineering and project management, and that "it works". This positive perspective is congruent with the concepts of opportunities vs. risks, with requisite complexity, viable systems, and with antifragility (Taleb N. N., 2012). Thus, the theories of appropriate and positive complexity are of particular interest, as basis and catalyst for creating and exploiting project opportunities. 


\section{REFERENCES}

Baccarini, D. (1996). The concept of project complexity, a review. International Journal of Project Management, 14(4), 201-204. doi:10.1016/0263-7863(95)00093-3

Bakhshi, J., Ireland, V., \& Gorod, A. (2016). Clarifying the project complexity construct: Past, present and future. International Journal of Project Management, 34(7), 1199-1213. doi:10.1016/j.ijproman.2016.06.002

Bansal, P., \& Corley, K. (2012). Publishing in AMJ-Part 7: What's Different about Qualitative Research? Academy of Management Journal, 55(3), 509-513. doi:10.5465/amj.2012.4003

Bar-Yam, Y. (2003). When Systems Engineering Fails --- Toward Complex Systems Engineering. SMC'03 Conference Proceedings. 2003 IEEE International Conference on Systems, Man and Cybernetics. Conference Theme - System Security and Assurance.

Beer, S. (1972). Brain of the Firm. The Penguin Press.

Bjorvatn, T., \& Wald, A. (2018). Project complexity and team-level absorptive capacity as drivers of project management performance. International Journal of Project Management, 36(6), 876-888. doi:10.1016/j. ijproman.2018.05.003

CDG. (2019). C. D., \& DMO, D. M. (2012). Defence capability plan public version. [from Australian Government Department of Defence.]. Retrieved, 05, 19.

Chyung, S. Y., Roberts, K., Swanson, I., \& Hankinson, A. (2017). Evidence-Based Survey Design: The Use of a Midpoint on the Likert Scale. Performance Improvement, 56(10), 15-23. doi:10.1002/pfi.21727

Daniel, P. A., \& Daniel, C. (2018). Complexity, uncertainty and mental models: From a paradigm of regulation to a paradigm of emergence in project management. International Journal of Project Management, 36(1), 184-197. doi:10.1016/j.ijproman.2017.07.004

Dao, B. P. (2016). Exploring and measuring project complexity. Texas A\&M University.

Edmonds, B. (1999). Syntactic measures of complexity - Thesis of the University of Manchester for the degree of doctor of philosophy in the faculty of arts. Academic Press.

European Court of Auditors. (2014). Lessons from the European Commission's development of the second generation Schengen Information System (SIS II). Luxembourg: European Court of Auditors. doi:10.2865/8113

Floricel, S., Michel, J. L., \& Piperca, S. (2016, October). Complexity, uncertainty-reduction strategies, and project performance. International Journal of Project Management, 34(7), 1360-1383. doi:10.1016/j. ijproman.2015.11.007

Flyvbjerg, B., \& Budzier, A. (2011, September). Why Your IT Project May Be Riskier Than You Think. Harvard Business Review. Advance online publication. doi:10.2139/ssrn.2229735

GAPPS. (2007). A Framework for Performance Based Competency Standards for Global Level 1 and 2 Project Managers. GAPPS.

Geraldi, J., Maylor, H., \& Williams, T. (2011). Now, let's make it really complex (complicated): A systematic review of the complexities of projects. International Journal of Operations \& Production Management, 31(9), 966-990. doi:10.1108/01443571111165848

Gibbert, M., \& Ruigrok, W. (2010). The "What" and "How" of Case Study Rigor Three Strategies Based on Published Work. Organizational Research Methods, 13(4), 710-737. Advance online publication. doi:10.1177/1094428109351319

Gummesson, E. (2000). Qualitative Methods in Management Research. Sage.

Hass, K. B. (2008). Managing Complex Projects: A New Model. Management Concepts, Inc.

Kennedy, D. M., McComb, S. A., \& Vozdolska, R. R. (2011). An investigation of project complexity's influence on team communication using Monte Carlo simulation. Journal of Engineering and Technology Management, 28(3), 109-127. doi:10.1016/j.jengtecman.2011.03.001 
Levitt, H. M., Bamberg, M., Creswell, J. W., Frost, D. M., Josselson, R., \& Suárez-Orozco, C. (2018). Journal Article Reporting Standards for Qualitative Primary, Qualitative Meta-Analytic, and Mixed Methods Research in Psychology: The APA Publications and Communications Board Task Force Report. The American Psychologist, 73(1), 26-46. doi:10.1037/amp0000151 PMID:29345485

Marle, F., \& Vidal, L.-A. (2016). Managing Complex, High Risk Projects - A Guide to Basic and Advanced Project Management. Springer-Verlag.

Maurer, M. (2017). Complexity Management in Engineering Design - a Primer. Springer Berlin Heidelberg. doi:10.1007/978-3-662-53448-9

McKelvey, B., \& Boisot, M. (2009). Redefining strategic foresight: 'Fast' and 'far' sight via complexity science. In Handbook of Research on Strategy and Foresight. Cheltenham, UK: Elgar.

Merriam, S. B. (2009). Qualitative research: A guide to design and implementation. Wiley.

Morcov, S., Pintelon, L., \& Kusters, R. J. (2020a). Definitions, characteristics and measures of IT Project Complexity - a Systematic Literature Review. International Journal of Information Systems and Project Management, 8(2), 5-21.

Morcov, S., Pintelon, L., \& Kusters, R. J. (2020b). IT project complexity management based on sources and effects: Positive, appropriate and negative. Proceedings of the Romanian Academy - Series A, 21(4).

Patanakul, P. (2014). Managing large-scale IS/IT projects in the public sector: Problems and causes leading to poor performance. The Journal of High Technology Management Research, 25(1), 21-35. doi:10.1016/j. hitech.2013.12.004

PMI. (2014). Navigating Complexity: A Practice Guide. Project Management Institute.

PMI. (2017). A Guide to the Project Management Body of Knowledge (PMBOK Guide) (6th ed.). Project Management Institute.

Spencer, D., \& Warfel, T. (2004, Apr 7). Card Sorting: A Definitive Guide. Boxes and Arrows.

Stacey, R. D. (1995). The science of complexity: An alternative perspective for strategic change processes. Strategic Management Journal, 16(6), 477-495. doi:10.1002/smj.4250160606

Standish Group. (1994). The CHAOS Report.

Standish Group. (2014). The CHAOS Report.

Taleb, N. N. (2012). Antifragile: things that gain from disorder. Random House.

Taleb, N. N. (2018). Skin in the game: hidden asymmetries of daily life. Penguin Books.

Treasury Board of Canada Secretariat. (2015, Aug 24). Project Complexity and Risk Assessment Tool. Retrieved May 19, 2019, from Government of Canada: https://www.canada.ca/en/treasury-board-secretariat/services/ information-technology-project-management/project-management/project-complexity-risk-assessment-tool.html

Turner, J., \& Cochrane, R. (1993). Goals-and-methods matrix: Coping with projects with ill defined goals and/or methods of achieving them. International Journal of Project Management, 11(11), 93-102. doi:10.1016/02637863(93)90017-H

Vidal, L.-A., Marle, F., \& Bocquet, J.-C. (2011). Measuring project complexity using the Analytic Hierarchy Process. International Journal of Project Management, 29(6), 718-727. doi:10.1016/j.jproman.2010.07.005

Whitty, S. J., \& Maylor, H. (2009). And then came Complex Project Management (revised). International Journal of Project Management, 27(3), 304-310. doi:10.1016/j.jproman.2008.03.004

Wieringa, R. J. (2014). Design Science Methodology for Information Systems and Software Engineering. Springer. doi:10.1007/978-3-662-43839-8

Williams, T. M. (2005, November). Assessing and moving on from the dominant project management discourse in the light of Project Overruns. IEEE Transactions on Engineering Management, 52(4), 497-508. doi:10.1109/ TEM.2005.856572 
Yin, R. K. (2011). Qualitative research from start to finish. New York: The Guilford.

Stefan Morcov specializes in the management of large complex international IT projects, up to hundreds of mil. Eur and millions of stakeholders. He is a Computer Science Engineer (UPB), MBA (Tiffin University US), PMP, and studied project and product management, software engineering, sales, marketing (Open University UK, UB). He is working on IT complexity management with the Katholieke Universiteit Leuven. His projects received various recognitions, including several Best Practice labels from the European Commission and 2 IPMA awards.

Liliane Pintelon is a full professor at the Faculty of Engineering Science, Katholieke Universiteit Leuven. She is head of the Centre for Industrial Management - Traffic \& Infrastructure, and of the Subdivision Maintenance and Health Care Logistics. Her research interests are in performance modeling of (socio-)technical systems with a focus on risk analysis and management.

Rob J. Kusters obtained his master's degree in econometrics at the Catholic University of Brabant in 1982 and his Ph.D. in operations management at the Eindhoven University of Technology in 1988. He is a professor of 'ICT and Business Processes' at the Dutch Open University in Heerlen, where he is responsible for the master program 'Business Process Management and IT'. He published over 100 papers in international journals and conference proceedings and co-authored six books. His research focuses on project and process performance, IT governance, software quality and software management. 